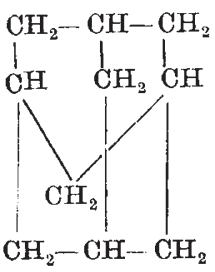

(I)

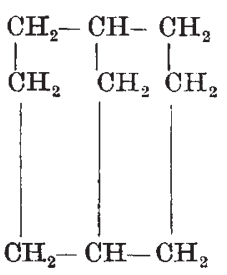

(Ii)

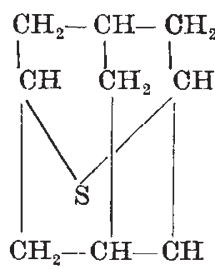

(111)

ization with Raney nickel, it yields bicyclo 1.3.3nonane (II).

While it is possible that the sulphur occupies alternative positions in the adamantane structure and that desulphurization still yields the same bicyclononane, from the general character of our compound it appears highly probable that the sulphur forms the second bridge spanning the 3.7-carbon atoms (III). An attempt is being made to confirm this structure by synthesis. The isolation of this compound together with that of the bicyclic sulphides and thiophenes which accompany it will be fully reported in due course elsewhere.

S. F. BIRCH

T. V. Cullum

R. A. DEAN

R. L. DENYER

Research Station,

Anglo-Iranian Oil Co., Ltd.,

Sunbury-on-Thames, Middlesex.

April 8.

${ }^{1}$ Coll. Trav. chem. Tchecoslovaquie, 5, 1 (1933).

Ber., 74, 1644 (1941).

\title{
Reduction of Tropinone with Lithium Aluminium Hydride
}

$\mathrm{THE}$ reduction of the keto group in tropinone (I) to the secondary alcoholic stage gives the two internally compensated stereoisomerides tropine and $\psi$-tropine (II). The nature of the reduction product depends on the reducing agent used. When the reduction is done electrolytically or with zinc and hydriodic acid, tropine is the main product ${ }^{1}$. However, the reduction product is always contaminated with small amounts of $\psi$-tropine. With sodium amalgam tropinone is reduced to $\psi$-tropine only ${ }^{1}$. As the formation of tropine and $\psi$-tropine from tropinone involves the reduction of a ketone to a secondary alcohol, it could be forcseen that lithium aluminium hydride would be a specific reagent for $\mathrm{it}^{2}$. However, the interest lay in knowing the exact nature of the reduction product (or products) obtained.

Reduction of tropinone was studied in ether solutions. In all the experiments $\psi$-tropine was<smiles>CN1[C@H]2CC[C@@H]1CC(=O)C2</smiles>

(1)

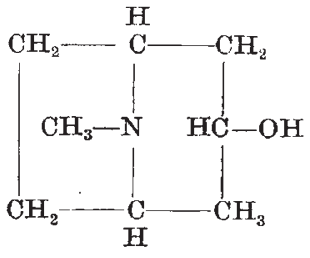

(II) obtained and the yield was quantitative. Difference in the concentration of the solution, in the rate of addition, or reverse addition, made no change in the nature of the reduction product. A range of temperatures from $-10^{\circ}$ to the boiling point of ether made no difference. In all the experiments, the product was isolated in the form of the picrate to ensure the separation of tropine and $\downarrow$-tropine ${ }^{1,3}$.

\section{Central Laboratories,}

Rafat Mirza Hyderabad. Feb. 17.

1 Willstätter, Ber., 33, 1167 (1900).

${ }^{2}$ Brown, J. Amer. Chem. Soc., 69, 1197 (1947).

${ }^{3}$ Ladenburg, Ber., 35, 1159 (1902).

\section{A New Province of Igneous Ring- Complexes in Southern Nyasaland}

RECENT examination of air photographs of Southern Nyasaland taken by the Royal Air Force has revealed that almost certainly this area forms a province of igneous ring-complexes, vents and dykes comparable with the British Tertiary igneous area of West Scotland, the White Hart Mountains region of New Hampshire and the more recently described region of ring intrusions in Nigeria. Indeed, it seems probable that the number of vents and ring-complexes in Southern Nyasaland and the adjoining parts of Portuguese territory will exceed that of any previously reported area.

From Dr. F. Dixey's work ${ }^{1}$ on the Nyasaland Geological Survey, it has long been known that vents filled with agglomerates and the much-discussed carbonatites exist in the region of Lake Chilwa, and it now appears likely that these form one manifestation in a complete igneous episode involving, in order of time, great outpourings of lava, the explosion of volcanic vents, probable cauldron-subsidence and the intrusion of ring-dykes and great syenite stocks and, lastly, the injection of basic dykes. 'The Stormberg period at the close of Karroo times was characterized by the extrusion of tremendous lava flows over a very large area in Central and South Africa, and Dr. Dixey has been able to date the volcanic vents of Southern Nyasaland as being post-Karroo and preCretaceous. Further, it is known that the nepheline syenite intrusions into the vents are later than the agglomerates and carbonatites and, while the great ring-dyke complexes now reported have not yet been dated, there is very good reason to suppose, from analogy with other areas, that they follow on, in time, after the explosive vents and were themselves followed by the dyking phase.

One very spectacular ring-dyke complex forms Chambe Plateau in the north-western part of the Mlanje Mountains; it is thought to comprise four successive ring-dykes about the same centre and with a common vertical axis. The external diameter of the outermost dyke is just over four miles. From the plains at the foot of the mountains the two outer 'rings' rise almost sheer for $6,000 \mathrm{ft}$. in places, while the two inner 'rings' form a central circular depressed region some $2,000-2,500 \mathrm{ft}$. below the outer 'rampart'.

The facts observed on the photographs and the hypotheses formed therefrom must, of course, be checked in the field before this potentially important region can be discussed in detail ; but the recognition 